\title{
Sorovares de Salmonella isolados de matérias-primas e de ração para aves no Brasil ${ }^{1}$
}

\author{
Ernesto Hofer ${ }^{2}$, Sebastião Januário da Silva Filho ${ }^{2,3}$ e Eliane Moura \\ Falavina dos Reis ${ }^{2}$
}

\begin{abstract}
Hofer E., Silva Filho S.J. \& Reis E.M.F. 1998. [Salmonella serovars isolated from feedstuff and poultry feeds in Brazil.] Sorovares de Salmonella isolados de matérias-primas e de ração para aves no Brasil. Pesquisa Veterinária Brasileira 18(1):21-27. Depto Bacteriologia, Instituto Oswaldo Cruz/FIOCRUZ, Rio de Janeiro, RJ 21045-900, Brazil.

Salmonella strains were isolated from feedstuff and poultry feeds from several regions of Brazil in 1976 and from 1979 to 1991 . Serotyping of 2293 isolates showed 151 serovars which pertained to 17 serogroups and were classified as subspecies I $(99.6 \%)$, III $(0.33 \%)$ and IV $(0.04 \%)$. There was a predominance of groups 0:7 (30.4\%), 0:4 (24.5\%), 0:3,10 (19.1\%), 0:13 $(7.8 \%), 0: 1,3,19(4.9 \%)$ and $0: 18(3.7 \%)$, representing $90 \%$ of the serogroups characterized that accounted for 103 different serotypes $(68.2 \%)$. Predominant serovars isolated from all sources were $S$. Montevideo, $S$. Senftenberg, $S$. Havana, $S$. Mbandaka, $S$. Tennessee, $S$. Infantis, $S$. Agona, $S$. Anatum, $S$. Cerro and $S$. Bredeney. Bacteriological and epidemiological aspects and the relationship with serovars isolated from poultry are discussed.
\end{abstract}

INDEX TERMS: Poultry feeds, Salmonella, serogroup, serovar, prevalence.

RESUMO.- Foram caracterizadas antigenicamente amostras de Salmonella isoladas de matérias-primas e de ração para aves em 1976 e durante doze anos consecutivos (1979-1991). As 2293 culturas analisadas provieram de sete regiões distintas do país e possibilitaram o reconhecimento de 151 sorovares, classificados bioquimicamente nas subespécies I $(99,6 \%)$ III $_{\mathrm{a}}(0,33 \%)$ e IV $(0,04 \%)$, respectivamente. Os sorovares identificados se distribuiram por 17 sorogrupos, com predominância de 0:7 (30,4\%), 0:4 (24,5\%), 0:3,10 (19,1\%), 0:13 $(7,8 \%), 0: 1,3,19(4,9 \%)$ e $0: 18(3,7)$, que representam $90 \%$ dos grupos sorológicos caracterizados e constituídos de 103 $(68,2 \%)$ sorotipos. Dentre os dez sorovares mais frequentemente reconhecidos citam-se $S$. Montevideo, $S$. Senftenberg, $S$. Havana, $S$. Mbandaka, $S$. Tennessee, $S$. Infantis, $S$. Agona, $S$. Anatum, $S$. Cerro e $S$. Bredeney. Alguns aspectos de caráter epidemio-lógico foram discutidos, envolvendo particularmente, determinados sorotipos e inclusive confrontando-se os resultados obtidos com aqueles oriundos de investigação conexa em aves.

TERMOS DE INDEXAÇÃO: Matéria-prima, ração, aves, Salmonella, sorogrupos, sorovares.

\footnotetext{
${ }^{1}$ Aceito para publicação em 18 de setembro de 1997.

2 Depto Bacteriologia, Instituto Oswaldo Cruz/FIOCRUZ, Av. Brasil 4365, Manguinhos, Rio de Janeiro, RJ 21045-900

${ }^{3}$ In memoriam, falecido em 10 de janeiro de 1989.
}

\section{INTRODUÇÃO}

Na atualidade as salmoneloses ocupam uma das posições mais destacadas no campo da saúde pública em todo o mundo, exteriorizando-se pelas suas características de endemicidade, morbidade e, em particular, pela dificuldade de seu controle. Todo este corolário decorre dos múltiplos parâmetros epidemiológicos envolvidos, circunstanciados, principalmente pelas inúmeras fontes de infecção e vias de transmissão presentes no ciclo (Hofer \& Reis 1994). Sem dúvida que neste problema, a salmonelose animal, com ênfase para as aves se destaca e, tendo como vínculo indissimulável, as rações e seus ingredientes (Edwards \& Galton 1967).

Já é um ponto notório, que a ração tendo em sua constituição insumos de origem animal, como as farinhas de carne, ossos, peixe, penas, vísceras, quando não tratadas convenientemente, se constituem em um problema crucial na introdução das salmonelas no plantel avícola (Boyer et al. 1962).

No presente trabalho foi analisada a ocorrência de sorovares de Salmonella, em rações e/ou seus componentes, durante vários anos.

\section{MATERIAL E MÉTODOS}

Em 1976 e em 12 anos consecutivos (1979-1991), o Laboratório de Enterobactérias do Instituto Oswaldo Cruz (IOC), examinou 2293 amostras de Salmonella isoladas de rações e seus insumos (farinhas de origem animal), oriundas de diferentes partes do país (Quadro 1). 
Quadro 1. Distribuição das salmonelas analisadas em 1976 e no período de 1979 a 1991 por área geográfica

\begin{tabular}{ccccccccc}
\hline \multirow{2}{*}{ Ano } & \multicolumn{7}{c}{ Origem } & \\
\cline { 2 - 5 } & $\begin{array}{c}\text { Santa } \\
\text { Catarina }\end{array}$ & Paraná & $\begin{array}{c}\text { São } \\
\text { Paulo }\end{array}$ & $\begin{array}{c}\text { Rio de } \\
\text { Janeiro }\end{array}$ & $\begin{array}{c}\text { Minas } \\
\text { Gerais }\end{array}$ & Goiás & $\begin{array}{c}\text { Distrito } \\
\text { Federal }\end{array}$ & Total \\
1976 & - & 76 & - & - & 5 & - & - & 8 \\
1979 & 15 & - & - & - & 2 & - & - & 17 \\
1980 & 6 & - & - & - & - & - & - & 6 \\
1981 & 12 & - & - & - & 1 & 23 & - & 36 \\
1982 & 23 & - & - & - & 37 & - & - & 60 \\
1983 & 40 & - & 69 & 5 & 34 & - & - & 148 \\
1984 & 293 & - & - & 7 & - & - & - & 307 \\
1985 & 95 & - & - & - & 9 & - & - & 104 \\
1986 & 67 & - & 2 & - & 34 & - & - & 103 \\
1987 & 116 & - & 2 & - & 5 & - & - & 123 \\
1988 & 178 & - & 12 & - & 6 & - & - & 196 \\
1989 & 179 & - & - & - & 12 & - & - & 191 \\
1990 & 669 & - & - & - & 19 & - & - & 688 \\
1991 & 152 & - & 15 & - & 10 & 7 & 49 & 233 \\
Total & 1845 & 76 & 100 & 12 & 181 & 30 & 49 & 2293
\end{tabular}

As cepas foram remetidas por entidades privadas $(2106=91,8 \%)$ e por instituições públicas $(187=8,1 \%)$. Via de regra, esta remessa se fazia em tubos contendo agar nutriente ou em outros meios básicos, isentos de carboidratos. É importante salientar que em mais de $80 \%$ das amostras não se tinha uma informação específica sobre os tipos de ração ou farinha, que possibilitaram o isolamento de Salmonella, embora em todos estava assinalada de forma genérica, como origem, os termos ração ou farinha para ração de aves.

As culturas foram analisadas quanto a sua pureza, através do reisolamento em meio seletivo-indicador (Agar EMB-Difco) e, em sequência, selecionou-se três colônias em fase lisa, visando a caracterização do perfil bioquímico compatível para o gênero e subespécies de Salmonella (Costa \& Hofer 1972, Le Minor \& Popoff 1987).

A identificação sorológica foi realizada após a comprovação bioquímica, sendo concretizada pela determinação das estruturas antigênicas somáticas e flagelares, através do processo de soro- aglutinação rápida (Costa \& Hofer 1972). Nesta etapa foram utilizados antissoros polivalentes e monovalentes, somáticos e flagelares, produzidos pelo Laboratório de Enterobactérias, IOC/FIOCRUZ.

Na representação dos sorovares adotou-se a nomenclatura preconizada por Le Minor \& Popoff (1987).

\section{RESULTADOS}

As 2293 amostras de Salmonella analisadas antigenicamente, permitiram a identificação de 151 sorovares e de culturas em fase rugosa (Quadro 3).

Os sorotipos, predominantemente enquadrados na subespécie I (2285=99,6\%, incluindo as formas rugosas) se distribuiram por 17 sorogrupos, cujas frequências estão assinaladas nos Quadros 2 e 3. No Quadro 2, complementa-se, com a ocorrência de sorovares por ano, ordenados pelos respectivos sorogrupos.

Um detalhe que chama atenção nesses resultados, referese que naqueles sorogrupos mais incidentes, o número de sorovares reconhecidos por ano, dificilmente ultrapassa a $50 \%$ do total de sorotipos identificados, excetuando-se no grupo 0:7 $(65,2 \%)$. É importante também assinalar que esse problema não tem uma relação estreita com o número de amostras analisadas, como pode ser observado nos Quadros 1 e 2.

Por outro lado, salienta-se no Quadro 3 que os sorogrupos prevalentes 0:7 $(30,4 \%), 0: 4(24,5 \%)$ e 0:3,10 $(19,1 \%)$ representam $74 \%$ do total das amostras analisadas e estão constituídos de 82 sorovares $(54,3 \%)$. Com a adição dos sorogrupos subsequentes, 0:13 (7,8\%), 0:1,3,19 (4,9\%) e 0:18 (3,7\%), perfazem 90\% dos sorogrupos ocorrentes, envolvendo 103 sorovares ou $68,6 \%$ do total.

Os sorovares mais frequentes por origem geográfica e por ano de isolamento, foram registrados nos Quadros 4 e 5, sendo que neste último ainda se procurou estabelecer uma associação com os resultados obtidos nos espécimes de aves (Hofer et al. 1997), no período em questão. Com base nos dados do Quadro 4, verifica-se que os 22 sorotipos mais

Quadro 2. Distribuição dos sorovares identificados pelos respectivos sorogrupos e de acordo com o ano de isolamento

\begin{tabular}{|c|c|c|c|c|c|c|c|c|c|c|c|c|c|c|c|c|c|c|}
\hline Sorogrupos & $0: 4$ & 0:7 & $0: 8$ & $0: 9$ & $0: 9,46$ & $0: 3,10$ & $0: 1,3,19$ & O:11 & $0: 13$ & $0: 6,14$ & $0: 16$ & $0: 18$ & $0: 21$ & $0: 28$ & $0: 30$ & $0: 35$ & $0: 47$ & Total \\
\hline Sorovares & $n=29^{a}$ & $n=23$ & $\mathrm{n}=12$ & $\mathrm{n}=9$ & $\mathrm{n}=2$ & $\mathrm{n}=30$ & $\mathrm{n}=2$ & $\mathrm{n}=1$ & $\mathrm{n}=17$ & $n=6$ & $\mathrm{n}=4$ & $\mathrm{n}=2$ & $\mathrm{n}=4$ & $\mathrm{n}=4$ & $\mathrm{n}=3$ & $\mathrm{n}=2$ & $n=1$ & $\mathrm{n}=151$ \\
\hline 1976 & 5 & 4 & 1 & 1 & - & 11 & - & - & 5 & - & - & - & 1 & - & - & - & - & 28 \\
\hline 1979 & 1 & 2 & 1 & 1 & - & 3 & 1 & - & - & - & - & 1 & - & - & - & - & - & 10 \\
\hline 1980 & 1 & - & - & 1 & - & - & - & - & - & - & - & - & - & - & - & - & - & 2 \\
\hline 1981 & 3 & 4 & 2 & - & - & 5 & - & - & 1 & - & - & 1 & - & - & - & - & - & 16 \\
\hline 1982 & 5 & 6 & - & 1 & - & 4 & 1 & - & 2 & - & 1 & 1 & 1 & 1 & - & - & - & 23 \\
\hline 1983 & 12 & 9 & 2 & 1 & - & 6 & 1 & - & 2 & 3 & - & - & 2 & - & - & - & - & 38 \\
\hline 1984 & 13 & 12 & 8 & 2 & 1 & 15 & 1 & - & 5 & 3 & 1 & 1 & - & 1 & 1 & - & - & 64 \\
\hline 1985 & 7 & 7 & 1 & 1 & 1 & 7 & 1 & - & 2 & - & - & 1 & - & 1 & - & 1 & - & 30 \\
\hline 1986 & 7 & 9 & 1 & 3 & - & 13 & 1 & - & - & - & - & 2 & - & - & - & - & - & 36 \\
\hline 1987 & 6 & 8 & 1 & 2 & - & 9 & 1 & - & 1 & - & - & 1 & - & 1 & 1 & - & - & 31 \\
\hline 1988 & 14 & 9 & 1 & 1 & - & 6 & 2 & - & 3 & - & - & 1 & - & 1 & 1 & 1 & - & 40 \\
\hline 1989 & 8 & 10 & 4 & 1 & - & 7 & 1 & 1 & 3 & - & - & 1 & 1 & 1 & 2 & - & - & 40 \\
\hline 1990 & 14 & 15 & 2 & 3 & - & 13 & 1 & 1 & 4 & - & 2 & 1 & 2 & - & 2 & - & 1 & 62 \\
\hline 1991 & 8 & 7 & 2 & 2 & - & 8 & 1 & - & 5 & - & - & 1 & 1 & 1 & 1 & 1 & - & 38 \\
\hline
\end{tabular}


Quadro 3. Distribuição dos sorovares de Salmonella identificados e classificados em seus sorogrupos

\begin{tabular}{|c|c|c|c|c|c|c|c|}
\hline Sorogrupos & Sorovares & Número & $\%$ & Sorogrupos & Sorovares & Número & $\%$ \\
\hline $0: 4(\mathrm{~B})^{\mathrm{a}}$ & Agona & 82 & 3,57 & $0: 9\left(D_{1}\right)^{a}$ & Enteritidis & 19 & 0,82 \\
\hline \multirow[t]{28}{*}{$\mathrm{N}=563(24,55 \%)$} & Bredeney & 78 & 3,40 & $\mathrm{~N}=56(2,44 \%)$ & Panama & 10 & 0,43 \\
\hline & Typhimurium $\mathrm{O}_{5}{ }^{+} / \mathrm{O}_{5}^{-}$ & 76 & 3,31 & & Dublin & 6 & 0,26 \\
\hline & Derby 5 & 56 & 2,44 & & Eastbourne & 4 & 0,17 \\
\hline & Saintpaul & 51 & 2,22 & & Berta & 3 & 0,13 \\
\hline & Heidelberg & 44 & 1,91 & & Gallinarum & 3 & 0,13 \\
\hline & Fyris & 41 & 1,78 & & Eschberg & 1 & 0,04 \\
\hline & Stanley & 24 & 1,04 & & S. I 9, 12:-:-c & 9 & 0,39 \\
\hline & Chester & 21 & 0,91 & & S. I 9, 12:d:- ${ }^{-b}(\mathrm{ODC}+)^{\mathrm{d}}$ & 1 & 0,04 \\
\hline & Brandenburg & 16 & 0,69 & $0: 9,46\left(D_{2}\right)^{\mathrm{a}}$ & Mayday & 1 & 0,04 \\
\hline & Schwarzengrund & 13 & 0,56 & $\mathrm{~N}=2(0,08 \%)$ & S. IV 9, 46:-:- $\mathrm{e}$ & 1 & 0,04 \\
\hline & $\begin{array}{l}\text { Sandiego } \\
\text { Reading }\end{array}$ & 12 & 0,52 & $0: 3,10\left(E_{1}\right)^{a}$ & Anatum & 80 & 348 \\
\hline & Reading & 10 & 0,43 & $\mathrm{~N}=440(19,18 \%)$ & Newlands & $\begin{array}{l}\text { ou } \\
77\end{array}$ & $\begin{array}{l}3,48 \\
3,35\end{array}$ \\
\hline & Schleissheim & 5 & 0,21 & & & 77 & 3,35 \\
\hline & Teddington & 4 & 0,17 & & Lexington & 59 & 2,57 \\
\hline & Kaapstad & 3 & 0,13 & & Give & 52 & 2,26 \\
\hline & Stanleyville & 3 & 0,13 & & Orion & 47 & 2,04 \\
\hline & Ayton & 2 & 0,08 & & Muenster & 43 & 1,87 \\
\hline & Bareilly & 2 & 0,08 & & London & 13 & 0,56 \\
\hline & Essen & 2 & 0,08 & & Nchanga & 11 & 0,47 \\
\hline & California & 1 & 0,04 & & Shangani & 6 & 0,26 \\
\hline & Duisburg & 1 & 0,04 & & Biafra & 4 & 0,17 \\
\hline & Kisangani & 1 & 0,04 & & Westhampton & 4 & 0,17 \\
\hline & Winneba & 1 & 0,04 & & Coquilhatville & 3 & 0,13 \\
\hline & S. I $4,12:-: 1,2^{\mathrm{b}}$ & 3 & 0,13 & & Elisabethville & 2 & 0,08 \\
\hline & S. I $1,4,12:-:^{-b}$ & 3 & 0,13 & & Meleagridis & 2 & 0,08 \\
\hline & S. I $4,12:-:^{-}$ & 3 & 0,13 & & Newington & 2 & 0,08 \\
\hline & S. I 4, 12:d:-b & 2 & 0,08 & & Stockholm & 2 & 0,08 \\
\hline & S. I $4,12: 1, \mathrm{v}:{ }^{\mathrm{b}}$ & 2 & 0,08 & & Anderlecht & 1 & 0,04 \\
\hline \multirow{23}{*}{$\begin{array}{l}0: 7\left(C_{1}\right)^{\mathrm{a}} \\
\mathrm{N}=699(30,48 \%)\end{array}$} & Montevideo & 158 & 6,89 & & Bolton & 1 & 0,04 \\
\hline & Mbandaka & 110 & $\begin{array}{l}0,09 \\
4,79\end{array}$ & & Illinois & 1 & 0,04 \\
\hline & Tennessee & 109 & 4,79 & & Kalina & 1 & 0,04 \\
\hline & Infantis & 87 & 3,79 & & Manila & 1 & 0,04 \\
\hline & Oranienburg & 72 & 3,18 & & Oxford & 1 & 0,04 \\
\hline & Ohio & 60 & 2,61 & & Vejle & 1 & 0,04 \\
\hline & Inganda & 20 & 0,87 & & Yaba & 1 & 0,04 \\
\hline & Isangi & 17 & $\begin{array}{l}0,0 / \\
0,74\end{array}$ & & S. I 3, 10:-:-b & 11 & 0,47 \\
\hline & Rissen & 12 & $\begin{array}{l}0,14 \\
0,52\end{array}$ & & S. I $3,10:-: 1,5^{\mathrm{b}}$ & 6 & 0,26 \\
\hline & Livingstone & 7 & 0,30 & & S. I $3,10:-: 1,6^{b}$ & 4 & 0,17 \\
\hline & Concord & 6 & 0,30 & & S. I 3, 10:lv:- & 3 & 0,13 \\
\hline & Lomita & $\begin{array}{l}6 \\
6\end{array}$ & $\begin{array}{l}0,26 \\
026\end{array}$ & & S. I 3, 10:r:-b & 2 & 0,08 \\
\hline & $\begin{array}{l}\text { Lomita } \\
\text { Bonn }\end{array}$ & $\begin{array}{l}6 \\
2\end{array}$ & $\begin{array}{l}0,20 \\
0,08\end{array}$ & & S. I 3, 10:b:-b & 1 & 0,04 \\
\hline & Colorado & 2 & 0,08 & $0: 1,3,19\left(\mathrm{E}_{4}\right)^{\mathrm{a}}$ & Senftenberg & 112 & 4,88 \\
\hline & Lille & 2 & 0,08 & $\mathrm{~N}=113(4,92 \%)$ & Taksony & 1 & 0,04 \\
\hline & Gabon & 1 & 0,04 & $\mathrm{O} \cdot 11(\mathrm{~F})^{\mathrm{a}}$ & Rubiclaw & 2 & 004 \\
\hline & S. I 6, 7:-:- b & 15 & 0,65 & $\begin{array}{l}0: 11(\mathrm{~F})^{\mathrm{a}} \\
N=2\left(0.08^{\circ}\right.\end{array}$ & Rubislaw & 2 & 0,04 \\
\hline & S. I 6, 7:lw:3-b & 3 & 0,13 & & & & \\
\hline & S. I 6, 7:-:enx ${ }^{\mathrm{b}}$ & 3 & 0,13 & $0: 13(G)^{\mathrm{a}}$ & Havana & 112 & 4,88 \\
\hline & S. I 6, 7:d:-b & 2 & 0,08 & $\mathrm{~N}=179(7,80 \%)$ & Grumpensis & 14 & 0,61 \\
\hline & S. I 6, 7:r:-b & 2 & 0,08 & & Cubana & 10 & 0,43 \\
\hline & S. I $6,7: \mathrm{b}:-\mathrm{b}$ & 1 & 0,04 & & Bristol & 4 & 0,17 \\
\hline & S. I 6, 7:lw:- b & 1 & 0,04 & & Poona & 4 & 0,17 \\
\hline $0.8\left(C^{-}-C^{-3}\right)^{a}$ & & & & & Fridenau & 3 & 0,13 \\
\hline \multirow{11}{*}{$\mathrm{N}=40(1,74 \%)$} & Kentucky & 11 & 0,47 & & Borbeck & 2 & 0,08 \\
\hline & Newport & 6 & 0,26 & & Worthington & 2 & 0,08 \\
\hline & Hadar & 6 & 0,26 & & Mississippi & 1 & 0,04 \\
\hline & Labadi & 4 & 0,17 & & Rauss & 1 & 0,04 \\
\hline & Tshiongwe & 4 & 0,17 & & Washington & 1 & 0,04 \\
\hline & Blockley & 2 & 0,08 & & S. I $13,22: f g:-b$ & 14 & 0,61 \\
\hline & Emek & 2 & 0,08 & & S. I 13, 22:d:- & 5 & 0,21 \\
\hline & Haart & 1 & 0,04 & & S. I 13, 23:lw:- ${ }^{-}$ & 3 & 0,13 \\
\hline & Manhattan & 1 & 0,04 & & S. I $13,22:-: 1,2^{\mathrm{b}}$ & 1 & 0,04 \\
\hline & Takoradi & 1 & 0,04 & & S. I $13,23: \mathrm{r}^{-\mathrm{b}}$ & 1 & 0,04 \\
\hline & S. I 6, 8:r:-b & 1 & 0,04 & & S. I 13, 23:-:-b & 1 & 0,04 \\
\hline
\end{tabular}


Quadro 3. (Cont.) Distribuição dos sorovares de Salmonella identificados e classificados em seus sorogrupos

\begin{tabular}{|c|c|c|c|c|c|c|c|}
\hline Sorogrupos & Sorovares & Número & $\%$ & Sorogrupos & Sorovares & Número & $\%$ \\
\hline \multirow{5}{*}{$\begin{array}{l}\text { O:6, } 14(\mathrm{H})^{\mathrm{a}} \\
\mathrm{N}=8(0,34 \%)\end{array}$} & Boecker & 3 & 0,13 & \multirow{5}{*}{$\begin{array}{l}\mathrm{O}: 28(\mathrm{M})^{\mathrm{a}} \\
\mathrm{N}=14(0,61 \%)\end{array}$} & S. I 21:b:-:-b & 3 & 0,13 \\
\hline & Charity & 1 & 0,04 & & Pomona & 9 & 0,39 \\
\hline & Mampeza & 1 & 0,04 & & Oskarshamn & 1 & 0,04 \\
\hline & Onderstepoort & 1 & 0,04 & & S. I 28:y:-b & 3 & 0,13 \\
\hline & Surat & 1 & 0,04 & & S. III a $28: \mathrm{z}_{10}:-\mathrm{f}^{\mathrm{f}}$ & 1 & 0,04 \\
\hline \multirow{4}{*}{$\begin{array}{l}\mathrm{O}: 16(\mathrm{I})^{\mathrm{a}} \\
\mathrm{N}=4(0,17 \%)\end{array}$} & Warragui & 1 & 0,04 & \multirow{3}{*}{$\begin{array}{l}0: 30(\mathrm{~N})^{\mathrm{a}} \\
\mathrm{N}=20(0,87 \%)\end{array}$} & \multirow{3}{*}{$\begin{array}{l}\text { Morehead } \\
\text { Urbana } \\
\text { S. I 30:-:- }\end{array}$} & 12 & 0,52 \\
\hline & $\begin{array}{l}\text { Malakal } \\
\text { Sabova }\end{array}$ & 1 & $\begin{array}{l}0,04 \\
0,04\end{array}$ & & & 7 & 0,30 \\
\hline & S. I $16: z_{36}:-b$ & $\begin{array}{l}1 \\
1\end{array}$ & $\begin{array}{l}0,04 \\
0,04\end{array}$ & & & 1 & 0,04 \\
\hline & S. I $16:=1,2^{\mathrm{b}}$ & 1 & 0,04 & \multirow{2}{*}{$\begin{array}{l}0: 35(0)^{\mathrm{a}} \\
\mathrm{N}=7(0,30 \%)\end{array}$} & \multirow{2}{*}{$\begin{array}{l}\text { Adelaide } \\
\text { Ealing }\end{array}$} & 6 & \multirow{2}{*}{$\begin{array}{l}0,26 \\
0,04\end{array}$} \\
\hline $0: 18(K)^{\mathrm{a}}$ & Cerro & 80 & 3,48 & & & 1 & \\
\hline $\mathrm{N}=85(3,70 \%)$ & S. III $18: z_{4}, z_{32}:-\mathrm{f}$ & 5 & 0,21 & \multirow{3}{*}{$\begin{array}{l}0: 47(X)^{\mathrm{a}} \\
\mathrm{N}=2(0,08 \%)\end{array}$} & S. III $47: \mathrm{z}_{4}, \mathrm{z}_{23}:{ }^{-\mathrm{f}}$ & 2 & 0,08 \\
\hline \multirow{3}{*}{$\begin{array}{l}\mathrm{O}: 21(\mathrm{~L})^{\mathrm{a}} \\
\mathrm{N}=24(1,04 \%)\end{array}$} & Minnesota & 19 & 0,82 & & \multirow{3}{*}{ Rugosab $^{b}$} & 35 & \multirow{3}{*}{1,52} \\
\hline & Ruiru & 1 & 0,04 & & & & \\
\hline & S. I 21:b:- & 3 & 0,13 & Total & & 2293 & \\
\hline
\end{tabular}

a ( ) Antiga representação dos sorogrupos.

b Salmonella subespécie I.

c Salmonella imóveis, mas bioquimicamente distintos de $S$. Gallinarum e $S$

Pullorum.

d ODC - Ornitina descarboxilase.

e Salmonella subespécie IV.

${ }^{f}$ Salmonella subespécie III a (antigo gênero Arizona, monofásica).

fequentemente identificados, constituídos de 1687 amostras, representaram $73,5 \%$ do total analisado. Salienta-se neste caso, a influência exercida pela amostragem de Santa Catarina, com $82,1 \%$ dos sorovares mais incidentes e que no cômputo geral (Quadro 1), atingiu a 75,1\% das amostras analisadas.
No Quadro 6, onde se estabeleceu um confronto do nível de frequência dos sorovares em relação ao número de isolamentos durante o período da análise, observou-se a maior ocorrência de $S$. Oranienburg (12 anos), embora este sorovar não tenha tido uma casuística proeminente.

Quadro 4. Distribuição dos sorovares mais frequentes e suas respectivas origens geográficas

\begin{tabular}{lcccccccc}
\hline & \multicolumn{7}{c}{ Origem } \\
\cline { 2 - 8 } Sorovar & $\begin{array}{c}\text { Santa } \\
\text { Catarina }\end{array}$ & Paraná & $\begin{array}{c}\text { São } \\
\text { Paulo }\end{array}$ & $\begin{array}{c}\text { Rio de } \\
\text { Janeiro }\end{array}$ & Minas & Gerais & & Federal \\
\hline Montevideo & 134 & 1 & 2 & - & 8 & - & 13 & 158 \\
Senftenberg & 93 & - & 5 & 1 & 8 & - & 5 & 112 \\
Havana & 101 & - & 2 & 5 & 1 & - & 3 & 112 \\
Mbandaka & 105 & - & - & - & 2 & 3 & - & 110 \\
Tennessee & 94 & 4 & 3 & - & 4 & 2 & 2 & 109 \\
Infantis & 60 & 1 & 12 & 2 & 7 & - & 5 & 87 \\
Agona & 56 & 4 & 5 & 2 & 13 & - & 2 & 82 \\
Anatum & 56 & 8 & 6 & - & 8 & 2 & - & 80 \\
Cerro & 75 & - & - & - & 4 & 1 & - & 80 \\
Bredeney & 60 & 4 & 9 & - & 4 & 1 & - & 78 \\
Newlands & 72 & 1 & - & 1 & - & 1 & 2 & 77 \\
Typhimurium & 50 & 2 & - & - & 21 & 1 & 2 & 76 \\
Oranienburg & 43 & 9 & 10 & - & 4 & 6 & 1 & 73 \\
Ohio & 54 & - & 3 & - & 3 & - & - & 60 \\
Lexington & 53 & - & - & 1 & 5 & - & - & 59 \\
Derby & 41 & 8 & 4 & - & 3 & - & - & 56 \\
Give & 44 & 2 & - & - & 3 & 3 & - & 52 \\
Saintpaul & 35 & - & 1 & - & 15 & - & - & 51 \\
Orion & 39 & - & - & - & 6 & - & 2 & 47 \\
Heidelberg & 44 & - & - & - & - & - & - & 44 \\
Muenster & 38 & 1 & 1 & - & 1 & - & 2 & 43 \\
Fyris & 39 & - & - & - & 2 & - & - & 41 \\
Total & 1386 & 45 & 63 & 12 & 122 & 20 & 39 & 1687 \\
\% & 82,15 & 2,66 & 3,73 & 0,71 & 7,23 & 1,18 & 2,31 & 99,97
\end{tabular}




\section{DISCUSSÃO}

As análises realizadas por inúmeros autores de diferentes partes do mundo, apontaram desde as observações iniciais de Griffin (1952), Galton et al. (1955) e Rohde \& Bischoff (1956) a participação efetiva dos insumos de origem animal e ração, na veiculação das salmonelas, para as várias fontes de infecção.

O problema adquiriu maior destaque devido ao extraordinário incremento da criação dos animais sob a forma intensiva e circunscrita cada vez mais a áreas bem delimitadas, tendo como nutrição básica, as rações. Este veículo, mesmo albergando um discreto número de células viáveis, pode se constituir no ponto de partida do processo de colonização de Salmonella num plantel (Schleifer et al. 1984). A propagação ou persistência desta bactéria numa população animal depende de alguns fatores, como por exemplo:

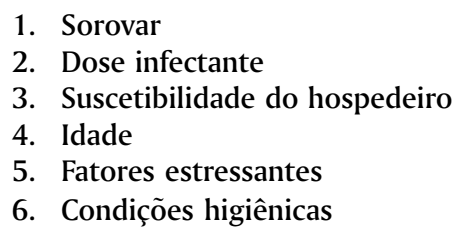

Salienta-se que a associação dos três primeiros aspectos, se constitui num elo fundamental, relacionando-os ao problema da maior ou menor facilidade de adaptação aos vários hospedeiros, com ênfase para as aves, das salmonelas caracterizadas como ubiquitárias. Um exemplo típico desta situação está retratado na propagação de Salmonella Agona nas décadas de 70 e 80 , que a partir da contaminação da farinha de peixe oriunda do Peru, se projetou inicialmente, entre as aves e de forma gradativa envolvendo outras fontes de infecção, culminando com a espécie humana (Clark et al. 1973, Guinee \& Valkenburg 1975). A literatura registra vários ou- tros acontecimentos desta natureza com outros sorovares (Hirsch \& Shapiro-Hirsch 1958, Le Minor et al. 1985) tendo na atualidade o destaque para $S$. Enteritidis (Rodrigue et al. 1990, Tauxe 1991). Por sinal, este problema tem características cosmopolitas, pois também na presente investigação observouse as ocorrências temporárias ou mais prolongadas dos sorovares Agona, Typhimurium, Saintpaul, Heidelberg, Mbaudaka, Infantis, Hadar, Panama, Anatum e no momento, Enteritidis (Quadros 3 e 4).

Outro fato digno de menção, reproduzido na maioria das investigações, refere-se ao elevado número de sorotipos reconhecidos. Assim, na presente análise foram caracterizados 151 sorovares classificados em 17 sorogrupos (Quadros 2 e 3). Provavelmente, a causa desse acontecimento decorre da mistura de um grande número de insumos de uma mesma qualificação, e talvez de fontes localizadas em diferentes origens. Este aspecto também retrata que as salmonelas tem uma ampla distribuição no reino animal e no meio ambiente, mas mantendo-se de uma forma silente, dificilmente detectada pelos processos usuais de isolamento. Na verdade, nos insumos se tem uma concentração dessas bactérias, embora sua repartição seja bastante heterogênea.

Depara-se ainda nesta análise com alguns outros aspectos de interesse epidemiológico, como a notável predominância dos sorotipos pertencentes a subespécie I de Salmonella, $(2285-99,6)$, restando apenas 8 amostras $(0,34 \%)$ classificadas nas subespécies IIIa e IV, entre as 2293 cepas tipificadas (Quadro 3). Aliás, esta situação coaduna-se com os dados apresentados pela maioria dos autores nacionais (Giorgi et al.1971, Silva et al. 1973, Miranda et al. 1978, Calzada et al. 1984, Hofer 1985, Berchieri Jr. et al. 1984, 1989 e 1993).

Confrontando com os resultados dos trabalhos supramencionados, observa-se a discreta detecção de S.

Quadro 5. Sorovares de Salmonella mais frequentes por ano nos insumos/ração e nas aves ${ }^{\mathrm{a}}$

\begin{tabular}{|c|c|c|}
\hline \multirow[b]{2}{*}{ Ano } & \multicolumn{2}{|l|}{ Sorovares } \\
\hline & Insumos/Ração & Aves \\
\hline 1976 & Anatum - Oranienburg [Derby - Typhimurium] ${ }^{b}$ & S. IIIa $18: \mathrm{z}_{4}, \mathrm{z}_{32} \mathrm{i}^{-\mathrm{C}}$ Derby - Typhimurium \\
\hline 1979 & S. IIIa $18: \mathrm{z}_{4}, \mathrm{z}_{32}:^{-{ }^{\mathrm{c}}}$ [Oranienburg-Enteritidis] & S. IIIa $18: \mathrm{z}_{4}, \mathrm{z}_{32}:^{-\mathrm{c}}$ Senftenberg \\
\hline 1980 & S. I 9,12:-:- ${ }^{2}$ Derby & Enteritidis - Oranienburg [Agona - Newlands] \\
\hline 1981 & Oranienburg - Tennessee - Isangi & Typhimurium - Kentucky [Derby - Tennessee] \\
\hline 1982 & Typhimurium [Saintpaul - Senftenberg] - Dublin & Saintpaul - Typhimurium [Infantis - Oranienburg] \\
\hline 1983 & Infantis - Inganda - Anatum [Bredeney - Saintpaul] & Schleissheim - Saintpaul - Infantis \\
\hline 1984 & Senftenberg - Oranienburg - Chester & Typhimurium - Montevideo - Isangi \\
\hline 1985 & Muenster - Anatum - Reading & Typhimurium - Tennessee - [Anatum - Heidelberg] \\
\hline 1986 & Montevideo - Infantis - Tennessee & [Typhimurium - Infantis] - Enteritidis - Hadar \\
\hline 1987 & Montevideo - [Mbandaka - Havana] - Cerro & Infantis - Typhimurium - Heidelberg \\
\hline 1988 & Montevideo - Cerro [Heidelberg - Mbandaka - Lexington] & Enteritidis - Infantis - Hadar \\
\hline 1989 & Ohio - Agona - Mbandaka & [Montevideo - Cerro] - [Agona - Orion] \\
\hline 1990 & Havana - Tennessee - Montevideo & Typhimurium - Heidelberg - Enteritidis \\
\hline 1991 & Montevideo - Mbandaka - Fyris & Typhimurium - Infantis - Mbandaka \\
\hline
\end{tabular}


Quadro 6. Frequência em anos e respectivos números de isolamentos dos sorovares mais incidentes de Salmonella no período de análise $(1976,1979$-1991)

\begin{tabular}{lccc}
\hline Sorovar & Sorogrupo & $\begin{array}{c}\text { Ocorrência } \\
\text { (anos) }\end{array}$ & $\begin{array}{c}\text { Número de } \\
\text { isolamentos }\end{array}$ \\
\hline Oranienburg & $0: 7$ & 12 & 73 \\
Montevideo & $0: 7$ & 11 & 158 \\
Senftenberg & $0: 1,3,19$ & 11 & 112 \\
Tennessee & $0: 7$ & 11 & 109 \\
Infantis & $0: 7$ & 11 & 87 \\
Typhimurium & $0: 4$ & 11 & 76 \\
Lexington & $0: 3,10$ & 11 & 59 \\
Derby & $0: 4$ & 11 & 56 \\
Give & $0: 3,10$ & 11 & 52 \\
Agona & $0: 4$ & 10 & 82 \\
Anatum & $0: 3,10$ & 10 & 80 \\
Cerro & $0: 18$ & 10 & 80 \\
Newlands & $0: 3,10$ & 10 & 77 \\
Bredeney & $0: 4$ & 9 & 78 \\
Orion & $0: 3,10$ & 9 & 47 \\
Havana & $0: 13$ & 8 & 112 \\
Mbandaka & $0: 7$ & 8 & 110 \\
Muenster & $0: 3,10$ & 8 & 43 \\
Saintpaul & $0: 4$ & 7 & 51 \\
Heidelberg & $0: 4$ & 7 & 44 \\
Fyris & $0: 4$ & 6 & 41 \\
Ohio & $0: 7$ & 4 & 60 \\
& & &
\end{tabular}

Typhimurium, referida apenas por Calzada et al. (1984), assim como, a ausência de menção ao sorovar Enteritidis. Em contraposição, na presente investigação não possibilitou o reconhecimento de $S$. Eimsbuettel, relativamente comum nas análises efetuadas em São Paulo (Miranda et al. 1978, Calzada et al. 1984 e Berchieri Jr. 1984). Todavia um ponto que merece ser destacado, situa-se na compatibilidade bastante acentuada dos sorovares mais frequentemente identificados no Brasil.

Sob o prisma do diagnóstico sorológico, o conhecimento do nível de ocorrência dos sorovares de Salmonella, só tende a facilitar e economizar em tempo e material a etapa de caracterização das estruturas antigênicas somáticas e flagelares.

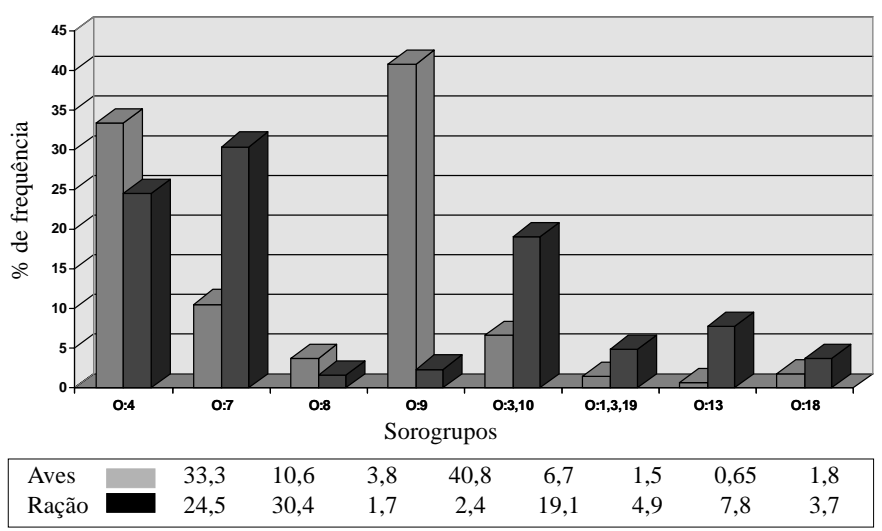

Fig. 1. Percentual dos sorogrupos de Salmonella mais incidentes em insumos/ração em relação ao das aves.
Assim, considerando os sorogrupos mais incidentes, $0: 7 ; 0: 4$; $0: 3,10 ; 0: 13 ; 0: 1,3,19$ e $0: 18$, nota-se que representam $90 \%$ da amostragem e constituídos por 103 sorovares $(68,6 \%)$. Curiosamente, este é um fenômeno que se mantém relativamente estável no correr do tempo, como pode ser analisado no Quadro 2. No entanto, alerta-se que de região para região, os sorovares mais frequentes apresentam variações, como se tem naqueles oriundos de Santa Catarina, Minas Gerais e São Paulo (Quadro 4). É bem provável que isto resulte dos tipos e origem das farinhas analisadas, que infelizmente, não foram especificadas na remessa das culturas. Sem dúvida, que esta particularidade também tenha tido uma implicância sobre os sorovares mais incidentes por ano (Quadro 5), no qual observa-se que excetuando $S$. Montevideo, não houve uma relação estreita entre a primeira posição ocupada com a frequência de isolamentos obtidos (Quadro 4).

A discrepância mais evidente dos achados se localiza no sorogrupo 0:9 (Fig. 1), resultado da acentuada prevalência nas aves de $S$. Gallinarum e $S$. Pullorum (Hofer et al. 1997), excepcionalmente reconhecidos nas matérias-primas e rações. Ainda assim, infere-se a importância da veiculação de Salmonella na população animal através das rações, respaldada na análise da frequência dos sorovares por ano (Quadro 5).

A análise do Quadro 6 ressalta mais uma vez o ponto anteriormente discutido sobre a racionalização ou simplificação das atividades no diagnóstico dos sorogrupos e sorovares. Assim, verifica-se por estes dados, que os 22 sorovares mais constantemente caracterizados, sete pertenciam ao sorogrupo $0: 4$, seis aos grupos $0: 7$ e $0: 3,10$, respectivamente, e um distribuído nos sorogrupos 0:1,3,19, 0:13 e 0:18, totalizando 1687 amostras ou $73,5 \%$ de todas aquelas analisadas.

Outra faceta de importância epidemiológica reside na premissa de que aqueles sorovares constantemente reconhecidos num período mais longo (Quadro 6), são os que sensibilizam mais os animais que ingerem de forma contínua essas rações contaminadas, resultando na infecção, ou num estágio de portador temporário ou de doença. Desta maneira se estabelece um círculo vicioso, mantendo um processo de retroalimentação para aquela população, assim como, propiciando a projeção externa, isto é, envolvendo novas fontes de infecção culminando pela espécie humana.

Em algumas situações este processo de propagação se faz de uma maneira relativamente rápida, mesmo explosiva, como se registrou no passado para $S$. Agona e na atualidade, com a $S$. Enteritidis.

Agradecimentos.- À toda equipe do antigo Laboratório de Enterobactérias, Instituto Oswaldo Cruz, pela execução de algumas etapas e, particularmente, às instituições públicas e privadas pela remessa das amostras bacterianas.

\section{REFERÊNCIAS}

Berchieri Jr. A., Irino K., Neme S. N., Paulillo A. C., Calzada C. T., Ferreira S. A. \& Pessôa G. V. A. 1984. Contaminação por Salmonella em farinhas de origem animal utilizadas no preparo de ração. Pesq. Vet. Bras. 4(3):83-88.

Berchieri Jr. A., Adachi S. Y., Calzada C. T., Paulillo A. C., Schoken-Iturrino R. P. \& Tavechio A. T. 1989. Farinha de carne como fonte de Salmonella em granja avícola. Pesq. Vet. Bras. 9(1):9-12. 
Berchieri Jr. A., Fernandes S. A., Irino K., Quintana J. L. \& Santos A. J. 1993. Salmonella in poultry feeds in Brazil. Revta Microbiol., São Paulo, 24:22-25.

Boyer C. I. Jr., Narotsky S., Bruner D. W. \& Brown J. A. 1962. Salmonellosis in turkeys and chickens associated with contaminated feed. Avian Dis. 6:4350.

Calzada C. T., Neme S. N., Irino K., Kano E., Dias A. M. G., Fernandes S. A., Vaz T. M. I. \& Pessôa G. V. A. 1984. Sorotipos de Salmonella identificados no período 1977-1982, no Instituto Adolfo Lutz, São Paulo, Brasil. Revta Inst. Adolfo Lutz, São Paulo, 44:1-18.

Clark G. M., Kauffmann A. F., Gangarosa E. J. \& Thompson M. A. 1973. Epidemiology of an international outbreak of Salmonella agona. Lancet II (7828):490-493.

Costa G. A. \& Hofer E. 1972. Isolamento e identificação de Enterobactérias. Monografia, Inst. Oswaldo Cruz, Rio de Janeiro. 120 p.

Edwards P. R. \& Galton M. M. 1967. Salmonellosis. Adv. Vet. Sci. 11:1-63.

Galton M. M., Harless M. \& Hardy A. V. 1955. Salmonella isolations from dehydrated dog meals. J. Am. Vet. Med. Assoc. 126:57-58.

Giorgi W., Ohashi K. \& Araujo W. P. 1971. Farinha de carne e farinha de peixe como fontes de salmonelas para animais. Arqs Inst. Biológico, São Paulo, 38:59-62.

Griffin C. A. 1952. A study of prepared feeds in relation to Salmonella infection in laboratory animals. J. Am. Vet. Med. Assoc. 121:197-200.

Guinee P. A. M. \& Valkenburg J. 1975. Salmonella isolations in Netherlands 1966-1973. Zbl. Bakt. Hyg. I Abt. Orig. A 231:97-106.

Hirsch W. \& Shapiro-Hirsch R. 1958. The role of certain animal feeding stuffs, especially bone meal in the epidemiology of salmonellosis. Harefuah 54:5759.

Hofer E. 1985. Epidemiologia das salmoneloses: Incidência de sorotipos de Salmonella em aves e rações (matérias-primas) no período de 1966-1984, p. 100-124. In: Anais do IV Simpósio do Centro Nacional de Pesquisa em Suí- nos e Aves, I Simpósio Catarinense de Sanidade Agrícola. Embrapa - CNPSA Doc. 9, Chapecó, Santa Catarina.

Hofer E. \& Reis E. M. F. 1994. Salmonella serovars in food poisoning episodes recorded in Brazil from 1982 to 1991. Revta Inst. Med. Trop., São Paulo, 36:7-9.

Hofer E., Silva Filho S. J. \& Reis E. M. F. 1997. Prevalência de sorovares de Salmonella isolados de aves no Brasil. Pesq. Vet. Bras. 17(2):55-62.

Le Minor L., Le Minor S. \& Grimont P. A. D. 1985. Rapport quadriennal du Centre National des Salmonella sur l'origine et la répartition en sérotypes des souches isolées en France continentale au cours des années 1980 à 1983. Rev. Epidém. et Santé Publ. 33:13-21.

Le Minor L. \& Popoff M. Y. 1987. Designation of Salmonella enterica sp. nov. as the type and only species of the genus Salmonella. Int. J. Syst. Bacteriol. 37:465-468.

Miranda J. B. N., Pessôa G. V. A., Irino K. \& Calzada C. T. 1978. Ocorrência de Salmonella em farinhas utilizadas como matéria-prima na composição de rações de animais. Revta Inst. Adolfo Lutz, São Paulo, 38:157-160.

Rodrigue D. C., Tauxe R. V. \& Rowe B. 1990. International increase in Salmonella enteritidis: A new pandemic ? Epidemiol. Infect. 105:21-27.

Rohde R. \& Bischoff J. 1956. Die epidemiologische Bedeutung Salmonella infizierter Tierfuttermittel (insbesondere Knochenschrot und Fischmehl) als Quelle verschiedener Lebensmittelvergiftungen. Zbl. Bakt. Abt. I 159:145164.

Silva E. N., Reis R., Oliveira R. L. \& Ávila F. A. 1973. Salmonelas em farinhas de origem animal destinada à fabricação de rações. Arqs Esc. Vet. UFMG, Belo Horizonte, 25:169-173.

Schleifer J. H., Juven B. J., Beard C. W. \& Cox N. A. 1984. The susceptibility of chicks to Salmonella montevideo in artificially contaminated poultry feed. Avian Dis. 28:497-503.

Tauxe R. V. 1991. Salmonella: A postmodern pathogen. J. Food Protect. 54:563569. 